\title{
Dimeric Dipeptide Mimetics of Brain- Derived Neurotrophic Factor: Design and Biological Properties
}

\author{
Tatiana A Gudasheva ${ }^{1 *}$ and Sergey B Seredenin ${ }^{2}$ \\ ${ }^{1}$ Department of Medicinal Chemistry, Research Zakusov Institute of Pharmacology, Russia \\ ${ }^{2}$ Department of Pharmacogenetics, Research Zakusov Institute of Pharmacology, Russia \\ *Corresponding author: Tatiana A Gudasheva, Department of Medicinal Chemistry Research Zakusov, Institute of Pharmacology, Moscow, Russia
}



\begin{abstract}
BDNF may represent a beneficial therapeutically agent against a variety of neurological and psychiatric disorders, but bad pharmacokinetics complicate its clinical use. This article focuses on the design and BDNF-like biological properties of low-molecular weight dimeric dipeptide mimetics of BDNF free of these disadvantages.

Keywords: BDNF; ГСБ-106; Dipeptide; Low-molecular weight mimetic; Neuroprotection; Antidepressant-like activity

Abbreviations: TrkB: Tropomyosine-related Kinase B; BDNF: Brain-Derived Nurotrophic Factor; PI3K/AKT: Phosphatidylinositol 3-kinase/Protein Kinase B; MAPK/ERK: Mitogen-Activated Protein Kinase/Extracellular Signal-Regulated Kinase; MCAO: Middle Cerebral Artery Occlusion
\end{abstract}

\section{Introduction}

Brain-derived neurotrophic factor (BDNF) regulates the development and maintenance of the peripheral and the central nervous system predominantly through binding to the transmembrane receptor tyrosine kinase TrkB [1]. Moreover, BDNF is synthesized and released by pancreatic beta-cells and produces the insulinotropic effect [2]. Binding of BDNF with TrkB leads to the activation of various intracellular signaling pathways, including the PI3K/AKT and MAPK/ERK pathways, which are the most critical for the biological effects of BDNF [3].

BDNF is a potential therapeutic target in numerous neurological, mental and psychiatric disorders including depression [4]. However, the outcomes of several clinical trials using recombinant BDNF are disappointing [5,6] possibly because of the poor delivery and short in vivo half-life of BDNF. To address this problems, tremendous effort has been made to generate selective agonists of TrkB including peptide mimetics [7]. Bioactive BDNF exists in a form of a noncovalently linked homodimer. Each monomer contains seven beta strands connected by four hairpin loops, three of which are exposed outside (loops 1, 2, 4) and therefore may play a major role in the interaction with the receptor [8].

We designed the dimeric dipeptides based on the beta-turns of BDNF loops $1\left(-\mathrm{D}^{30}-\mathrm{M}^{31}-\mathrm{S}^{32}-\mathrm{G}^{33}-\right), 2\left(-\mathrm{V}^{44}-\mathrm{S}^{45}-\mathrm{K}^{46}-\mathrm{G}^{47}-\right)$ and $4\left(-\mathrm{D}^{93}-\mathrm{S}^{94}-\right.$ $\mathrm{K}^{95}-\mathrm{K}^{96}$-); respectively bis-(N-monosuccinyl-L-methionyl-L-serine) heptamethylenediamide (GSB-214), bis-(N-hexanoyl-L-seryl-Llysine) hexamethylenediamide (GTS-201) and bis-(N-monosuccinyl-L-seryl-L-lysine) hexamethylenediamide (GSB-106) [9-11] [Ru Patent №2410392, 2010; US Patent US 9,683,014 B2, 2017; CN Patent CN 102365294 B, 2016]. The beta-turn sequences of BDNF hairpin loops were chosen as the basis of design because they are most likely to interact with the receptor due to their accessibility.

These compounds were constructed according to the uniform plan the central fragment of beta-turn was saved, and the preceding amino acid residue was substituted by its bioisostere, C-terminal dimerization was performed using oligomethylenediamine spacer. We studied the biological properties of GSB-214, GTS-201 and GSB106. It was shown that all of them activate TrkB receptor and that they each have different post-receptor signaling patterns [10-13]. GSB-106 increased the levels of ERK and AKT kinase phosphorylation, whereas GSB-214 only increased the level of AKT phosphorylation and GTS-201 activated MAPK/ERK signaling cascade without affecting PI3K/AKT signaling.

The all dipeptides in concentrations of $10^{-5}-10^{-8} \mathrm{M}$ protected HT22 neuronal cells from the $\mathrm{H}_{2} \mathrm{O}_{2}$-induced oxidative stress $[9,10,14]$. Neuroprotective activity of the active in vitro compounds was studied in vivo in a model of ischemic stroke, induced by transient middle cerebral artery occlusion (MCAO) in rats. The dimeric dipeptides GSB-106 and GSB-214 statistically significantly 
decreased infarct volumes at the treatment beginning 4 hour after surgery [15]bis-(N-monosuccinyl-l-seryl-l-lysine. GSB-106 reduced this volume by $\sim 66 \%$ and GSB-214 by $\sim 28 \%$. Loop 2 mimetic GTS201 was inactive.

An interesting observation was that GSB-106 exhibited significant antidepressant activity in the forced swimming test in mice, while GSB-214 and GTS-201 did not $[9,10]$. These data suggest that the both MAPK/ERK and PI3K/AKT signaling pathways are necessary for the manifestation of antidepressant activity mediated by TrkB receptors. There is literature data that describes 7,8-dihydroxyflavone (7,8-DHF), a small molecular TrkB agonist with antidepressant-like properties that provokes the PI3K/AKT and MAPK/ERK activation [16,17].

The antidepressant-like activity of GSB-106 was confirmed in a number of rodent tests [18] including forced swim test in rats and mice, tail suspension test in mice, in Nomura water wheel test in rats and in a social defeat stress model of depression in mice. Notably it is orally bioactive $(0.05-5 \mathrm{mg} / \mathrm{kg})$ and is safe for chronic treatment $[19,20]$. GSB-106 was found to prevent stress-induced impairments of hippocampal neurogenesis [21] and stimulates hippocampal synaptogenesis [22] in mice.

Study of the antidiabetic effects (estimated from the degree of hyperglycemia and dynamics of body weight in C57Bl/6 mice with the streptozotocin -induced diabetes mellitus) of dipeptide mimetics of BDNF demonstrated [23] that GSB-214 which selectively activated PI3K/AKT possessed robust antidiabetic activity. GTS-201 selective activator of MAPK/ERK does not demonstrated any antidiabetic activity. GSB-106 activating both signaling pathways exhibited weak antidiabetic activity.

Like BDNF [24] dipeptide GSB-106 demonstrated antinoceptive effect. It significantly inhanced the pain threshold in the hot plate (by 29\%) and tail flick (by 50\%) tests in rats at $24 \mathrm{~h}$ point at dose $0.1 \mathrm{mg} / \mathrm{kg}$ i.e. [25]. As a result, we created dimeric dipeptide mimetics of BDNF loops 1, 2 and 4. It has been established that all these compounds activate the specific BDNF receptor TrkB and they each have different post-receptor signaling patterns. Mimetic loop 4 GSB-106 acts as a good lead compound for further development as a promising therapeutic.

\section{References}

1. Kaplan DR, Miller FD (2000) Neurotrophin signal transduction in the nervous system. Curr Opin Neurobiol 10(3): 381-391.

2. Krabbe KS, Nielsen AR, Krogh Madsen R, Plomgaard P, Rasmussen P, et al. (2007) BDNF and type 2 diabetes. Diabetologia 50(2): 431-438.

3. Minichiello L (2009) TrkB signalling partways in LTP and learning. Nat Rev Neurosci 10(12): 850-860.

4. Lee BH, Kim YK (2010) The roles of BDNF in the pathophysiology of major depression and in antidepressant treatment. Psychiatry Investig 7(4): 231-235.

5. Ochs G, Penn RD, York M, Giess R, Beck M, et al. (2000) A phase I/II trial of recombinant methionyl human brain derived neurotrophic factor administered by intrathecal infusion to patients with amiotrophic lateral sclerosis. Amiotroph ILateral Scler Other Motor Neuron Disord 1(3): 201-206.
6. Thoenen H, Sendther M (2002) Neurotrophins: from enthusiastic expectations through sobering experiences to rational therapeutic approaches. Nat Neurosci 5(Suppl): 1046-1050.

7. O'Leary PD, Huges RA (2003) Design of potent peptide mimetics of brain-derived neurotrophic factor. J Biol Chem 278(28): 25738-25744.

8. Robinson RC, Radziejewski, C, Stuart, DI, Jones EY (1995) The structures of the neurotrophin- 4 homodimer and the brain-derived neurotrophic factor/neurotrophin 4 heterodimer reveal a common Trk-binding site. Biochemistry 34: 4139-4146.

9. Gudasheva TA, Tarasyuk AV, Pomogaibo SV, Logvinov IO, Povarnina PYu, et al. (2012) Design and synthesis of dipeptide mimetics of the brain-derived neurotrophic factor. Russian Journal of Bioorganic Chemistry 38(3): 243-252.

10. Gudasheva TA, Tarasiuk AV, Sazonova NM, Povarnina PY, Antipova TA, et al. (2017) A novel dimeric dipeptide mimetic of the BDNF selectively activates the MAPK-Erk signaling pathway. Doklady Biochemistry and Biophysics 476(1): 291-295.

11. Tarasyuk AV, Pomogaibo SV, Kurilov DV, Gudasheva TA (2013) Synthesis of BDNF-mimetic dimeric dipeptide GSB-106, a potential neuroprotector drug. Pharmaceutical Chemistry Journal 47(1): 20-27.

12. Gudasheva TA, Logvinov IO, Antipova TA, Seredenin SB (2013) Brain-derived neurotrophic factor loop 4 dipeptide mimetic GSB-106 activates TrkB, Erk, and Akt and promotes neuronal survival in vitro. Doklady Biochemistry and Biophysics 451(1): 212-214.

13. Gudasheva TA, Logvinov IO, Povarnina PY, AntipovaTA, Seredenin SB (2015) Analysis of dependence of antidepressant properties of TrkB receptor ligands on MAP kinase pathway activation. Doklady Biochemistry and Biophysics 460: 20-22.

14. Logvinov IO, Antipova TA, Gudasheva TA, Tarasiuk AV, Antipov PI, et al. (2013) neuroprotective effects of dipeptide analogue of brain-derived neurotrophic factor GSB-106 in in vitro experiments. Bulletin of Experimental Biology and Medicine 155(3): 343-345.

15. Gudasheva TA, Povarnina PYu, Logvinov IO, Antipova TA, Seredenin SB (2016) Mimetics of brain-derived neurotrophic factor loops 1 and 4 are active in a model of ischemic stroke in rats. Drug Design Development and Therapy 10: 3545-3553.

16.Zhang JC, Yao W, Dong C, Yang C, Ren Q et al. (2015) Comparison of ketamine, 7,8-dihydroxyflavone, and ANA-12 antidepressant effects in the social defeat stress model of depression. Psychopharmacology (Berl) 32(23): 4325-4335.

17. Liu C, Chan CB, Ye K (2016) 7,8-dihydroxyflavone, a small molecular TrkB agonist, is useful for treating various BDNF-implicated human disorders. Transl Neurodegener 5: 2 .

18. Seredenin SB, Voronina TA, Gudasheva TA, Garibova TL, Molodavkin GM, et al. (2013) Antidepressant effect of dimeric dipeptide GSB-106, an original low-molecular-weight mimetic of BDNF. Acta Naturae 5(4): 105-109.

19. Talerova AV, Povarnina PYu, Blynskaya EV, Bueva EV, Gudasheva TA, et al. (2018) Antidepressive effect of GSB-106 dipeptide mimetic of brain-derived neurotrophic factor is reproduced in a peroral drug formulation form. Pharmaceutical Chemistry Journal 52(5): 15-17.

20. Garibova TL, Krayneva VA, Valdman EA, Gudasheva TA, Kotelnikova SO, et al. (2018) The study of the effects of dipeptide mimetic of a brain-derived neurotrophic factor with antidepressant activity during prolonger use and after withdraval. Reviews on Clinical Pharmacology and Drug Therapy 16(1): 28-33.

21. Gudasheva TA, Povarnina PY, Seredenin SB (2017) Dipeptide mimetic of the brain-derived neurotrophic factor prevents impairments of neurogenesis in stressed mice. Bull Exp Biol Med 162(4): 454-457.

22. Gudasheva TA, Povarnina PY, Antipova TA, Seredenin SB (2018) Dipeptide BDNF mimetic GSB-106 with antidepressant-like activity stimulates synaptogenesis. Dokl Biochem Biop hys 481(1): 225-227. 
23. Ostrovskaya RU, Yagubova SS, Gudasheva TA, Seredenin SB (2018) Antidiabetic properties of low-molecular weight BDNF mimetics depend on the type of activation of post-receptor signaling pathways. Bulletin of Experimental Biology and Medicine 164(6): 734-737.

24. Siusiak JA, Altar CA, Wiegand SJ, Lindsay RM (1994) Antinociceptive effect of brain-derived neurotrophic factor and neurotrophin -3. Brain Res 633(1-2): 326-330.
25. Konstantinopolsky MA, Gudasheva TA, Kolik LG (2016) The BDNF mimetic GSB-106 produces long-term analgesia and significant reduction of opiate withdrawal signs: comparison with dipeptide anxiolytic GB115 effects in rats. European Neuropsychopharmacology 26(2): 680681.

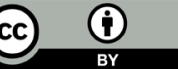

Creative Commons Attribution 4.0 International License

For possible submissions Click Here



